\title{
Short communication: Evaluation of an eating time sensor for use in pasture-based dairy systems
}

\author{
B. Dela Rue, ${ }^{1}$ J. M. Lee, ${ }^{1}$ C. R. Eastwood, ${ }^{1 *}$ ๑ K. A. Macdonald, ${ }^{1}{ }^{\oplus}$ and P. Gregorini ${ }^{2}$ \\ ${ }^{1}$ DairyNZ Ltd., Private Bag 3221, Hamilton 3240, New Zealand \\ ${ }^{2}$ Lincoln University, Department of Agricultural Sciences, Faculty of Agricultural and Life Sciences, Lincoln 7647, Christchurch, New Zealand
}

\begin{abstract}
The assessment of grazing behavior is important for research and practice in pasture-grazed dairy farm systems. However, few devices are available that enable assessment of cow grazing behavior at an individual animal level. This study investigated whether commercially available Smarttag "eating time" sensors (Nedap Livestock Management, Groenlo, the Netherlands) were suitable for recording the grazing time of cows. Smarttag sensors were mounted on the neck collars of multiparous Holstein-Friesian cows in a herd in Taranaki, New Zealand. Cows were randomly selected each observation day from the milking herd for 8 separate days across a 1-mo period. Trained observers conducted 90-min observation periods to evaluate the relationship between the sensor eating time measure and grazing time. A set of 5 defined cow behaviors (2 "head up" and 3 "head down" behaviors) were assessed. In total, observations of 37 cows were recorded in 14 sessions over $8 \mathrm{~d}$ in the study period, providing 55.5 total hours of observations. Observation data were aligned with sensor data according to the sensor time stamps and grouped into matching 15-min intervals. Interobserver reliability was assessed both before and after the main trial period, and the mean percentage eating time per observer had a coefficient of variation of $0.46 \%$ [mean 93.2, standard deviation (SD) 0.425] before and $0.07 \%$ (mean 96.3, SD 0.074) after. In the main trial, the relationship between observed (mean $70.8 \%$ ) and sensor-derived (mean 69.3\%) percentage eating time over the observation period gave a Pearson correlation coefficient of 0.971 , concordance correlation coefficient 0.968 , mean difference $1.50 \%$ points, and SD $5.8 \%$ points. Therefore, sensor-identified percentage "eating time" and observed percentage active grazing time were shown to be both very well correlated and concordant (in agreement, with high correlation
\end{abstract}

Received January 7, 2020.

Accepted May 19, 2020.

*Corresponding author: callum.eastwood@dairynz.co.nz and little bias). Therefore, the relationship between observed and sensor-derived data had a high degree of agreement for identifying cow grazing activity. In conclusion, Smarttag sensors are a valid and useful tool for estimating grazing activity at time periods of $1 \mathrm{~h}$ or more.

Key words: eating time sensor, grazing, animal behavior, precision dairy

\section{Short Communication}

Grazing behavior data has traditionally been collected using labor-intensive procedures (e.g., direct observation, time-lapse video recording) or expensive and sometimes fragile scientific sensors (Penning, 1983; Chizzotti et al., 2015). These methods are impractical for use over long time periods or with large numbers of animals. Thus, the appeal of automated behavior monitoring systems is increasing, particularly if such systems can assist in the estimation of herbage intake as well as help identify atypical behavior associated with compromised welfare or onset of disease (Greenwood et al., 2014; Van Erp-Van der Kooij et al., 2016). Many of the commercially available sensors - for example, the Smarttag "eating time" sensor - are used primarily in confinement housing systems, and limited research has been published regarding their application in pasturebased systems. Recent studies with the Smarttag sensor have focused on estrus detection (Roelofs et al., 2017), the transition period (Hut et al., 2019), and disease alerts (Eckelkamp and Bewley, 2020). The aim of this study was to evaluate the Smarttag eating time sensor for recording grazing activity of cows in pasture-based dairy systems. This information is important for researchers seeking to use the devices in grazing studies and for farmers considering investment in the devices.

This study was conducted at Gibson Farm, Dairy Trust Taranaki (formerly Westpac Taranaki Agricultural Research Station) in Hawera, New Zealand (39 $61^{\prime}$ S, $174^{\circ} 31^{\prime} \mathrm{E}, 110 \mathrm{~m}$ above sea level). All experimental procedures were approved by the Ruakura Animal Ethics Committee, New Zealand (AE 13292). 
The experiment was designed to evaluate whether the Smarttag "eating time" sensor (Version RealTime Neck, Nedap Livestock Management, Groenlo, the Netherlands) correctly identified grazing activity of cows in a pasture-based dairy system. The sensors record the timing of cow "head down" activity, which is associated with feed consumption. In a grazing scenario, head down activity tends to be associated with grazing; however, it could also include nongrazing behavior, such as searching for grass. Thus, to evaluate the relationship between the sensor eating time measure and observed grazing time, a set of defined cow behaviors were required. Based on previous literature (Moreau et al., 2009; Nielsen, 2013; Oudshoorn et al., 2013), 5 observable behaviors (B) were defined. The definitions were focused on 2 main postures, in which a cow had its head up or down. These postures were then subdivided to delineate between grazing, searching for pasture, masticating, and other behaviors, such as ruminating, lying, or idling. The 5 behaviors were as follows:

- B1. Head is up (above cow knee height) and the cow is masticating fresh grass while standing;

- B2. Head is up (above knee height) and the cow is exhibiting other behaviors, including ruminating or idling, and may not be standing;

- B3. Head is down (below knee height) while standing and the cow is actively grazing (biting, masticating);

- B4. Head is down (below knee height) while standing and the cow is searching for grass;

- B5. Head is down (below knee height) while standing and the cow is not grazing or searching.

These behaviors were loaded as 5 options in the "WhatISee" App (version 2.0, T. Hauser, Apple App Store; discontinued) on 4 iPads (Apple Inc., Cupertino, CA) with synchronized internal clocks. Four observers were trained to distinguish between the 5 grazing behaviors and to standardize their interpretations. All 4 observers then independently collected data on the grazing behavior of the same 1 cow for the same period of 30 min, and results were used to ascertain similarity of observer recordings. The mean percentage eating time per observer had a coefficient of variation of $0.46 \%$ (mean 93.2, SD 0.425). At the end of the trial the interobserver comparison was repeated, with all 4 observers again recording the behavior of 1 cow. In the repeat assessment the mean percentage eating time had a coefficient of variation of $0.07 \%$ (mean 96.3, SD 0.074).

As many multiparous Holstein-Friesian cows as required by observer availability were randomly selected from the milking herd on each of $8 \mathrm{~d}$ during December
2014 and January 2015, giving 37 cow-observer records. Smarttag sensors were mounted on the neck collar of each cow, identified by a number painted with tail paint (Skenandore and Cardoso, 2017) on both sides of the cow (rib area). Cow identification (ID) and collar ID were recorded. A separate area with temporary electric fencing was allocated for the observed cows within the same paddock as the milking herd. The first session began at $0930 \mathrm{~h}$, with a second session at $1130 \mathrm{~h}$, depending on observer availability. Behaviors of the cows were recorded for $90 \mathrm{~min}$. The pasture area was allocated to avoid competitive behavior and to allow normal socialization (approximately $300 \mathrm{~m}^{2}$ ). Sufficient pasture was provided (2,800-3,500 $\mathrm{kg}$ of DM/ha, visually assessed) to enable typical grazing behaviors. In total, observations were recorded for 37 cow-observer combinations over the study period, providing $55.5 \mathrm{~h}$ of observations.

The 90-min length of observation period was chosen to maximize the number of full 15-min sensor time periods while minimizing the time for which observers needed to concentrate continuously. At the start of each 90-min observation period, each observer recorded the initial behavior of their randomly allocated single cow on the preset WhatISee app, recording cow ID, behavior, and time stamp. When the cow changed to another of the 5 behaviors, the observer then selected this behavior on the WhatISee app, thereby creating a database of cow ID, observed behavior, and time stamp of the start of each different behavior session. Another study with the same sensor used observation periods of $8 \mathrm{~h} / \mathrm{d}$ (Van Erp-Van der Kooij et al., 2016), and Bikker et al. (2014) collected data on an ear-mounted feeding behavior sensor for 15 cows in 1- to 7-h sessions for $20 \mathrm{~h}$ of observations per cow across a 24-h period. A validation study of an ear tag sensor (Pereira et al., 2018) monitored 24 cows for a total of $6 \mathrm{~h} / \mathrm{cow}$, and another validation study involving 3 sensors (measuring activity and rumination) monitored 15 cows for $14 \mathrm{~h}$ from 0600 to $2000 \mathrm{~h}$ (Elischer et al., 2013). Although these studies had longer total observation times, they used fewer cows, and it is the number of experimental units that drives statistical power, usually more so than reducing variation per unit by increased subsampling. Additionally, the current study used an observation method that created continuous data through the 90min observation periods, compared with sampling at a per-minute frequency in other studies (Bikker et al., 2014; Pereira et al., 2018).

The Smarttag sensor registers the position (angle) and movement of the head of an animal using a 3-dimensional accelerometer mounted on a collar, positioned under the neck, as described by Hut et al. (2019). Software then estimates the time spent eating for each 
15-min period in $24 \mathrm{~h}$ and provides daily summaries for the user. Eating time was defined as behavior B3 from visual observations; however, in this grazing scenario, eating time (hereafter termed "grazing time") defined by the sensors may also include other head down behaviors (B3, B4, and B5).

Data were stored by each Smarttag sensor until it was close enough to the base receiver, situated near the dairy parlor, when the data were downloaded wirelessly. The base receiver then uploaded the data to a server via the cellular phone network, where they were processed and stored. The Smarttag system added a time stamp to data when they were downloaded. The base receiver aligned the data to the nearest previous predefined quarter-hour (in our experiment, those time stamps were 14, 29, 44, and 59 min past the hour). Based on the time difference between the Smarttag and base station, the data were adjusted by the Smarttag system to align with the nearest 15 -min period; therefore, the sensor recordings and the visual observations could be out of alignment by up to $15 \mathrm{~min}$. This time difference may give disagreements at the raw 15-min period level, especially if behavior has changed, but has less effect the more data are aggregated over time. The Smarttag classification of percentage eating time in each 15-min period is determined by proprietary algorithms. For this study, a weekly data file was provided by the sensor manufacturer, containing seconds of eating time in time-stamped 15-min blocks for each sensor.

Observation data were aligned with sensor data according to the sensor time stamps and grouped into matching 15-min intervals. This resulted in up to 5 complete 15-min intervals for both observations and sensor recordings within each 90-min observation period. The time spent actively grazing (B3) and the total time spent with head down (B3, B4, and B5) were then calculated for each interval. It is important to note that the sensor's "eating time" algorithm includes head up posture with movement associated with eating, so that eating time from feeding sources above the animal's knees (feed bins or troughs) is normally included. Data analysis looked at both raw 15-min interval data and averages of the 5 intervals.

For many observation periods, a high proportion of time was classified as actively grazing by both the observer (B3) and the sensor (i.e., data in top right corner of Figure 1). The relationship between observed (mean $70.8 \%$ ) and sensor-derived (mean $69.3 \%$ ) percentage time gave a Pearson correlation coefficient of 0.971 , concordance correlation coefficient (CCC) 0.968, mean difference $1.50 \%$ points, standard deviation $5.8 \%$ points. Figure 2 gives the Bland-Altman plot for this data and shows the $1.50 \%$ difference with $95 \%$ of data

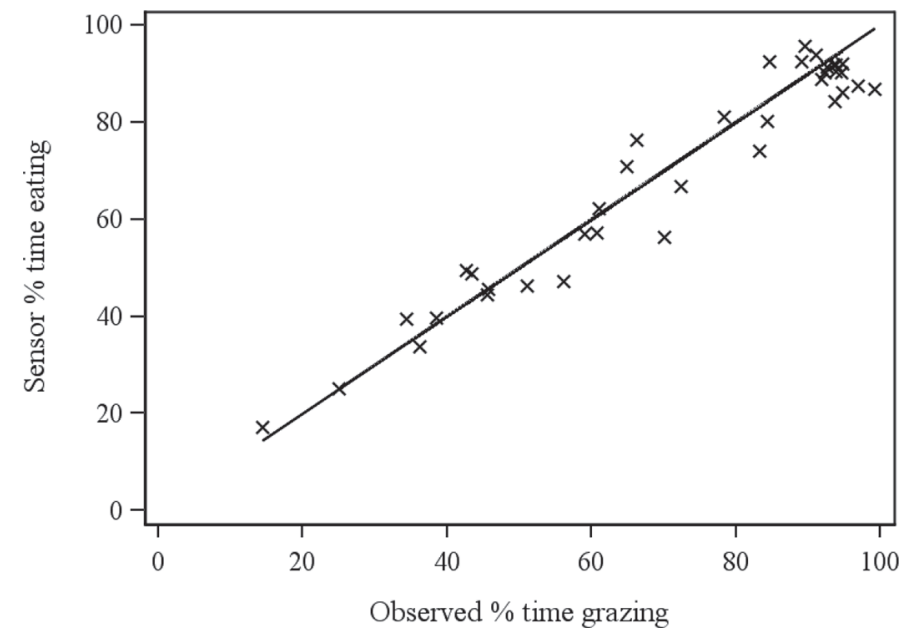

Figure 1. The relationship between mean percentage of observed time spent actively grazing, with mean percentage of time classified as grazing by the Smarttag "eating time" sensor (Nedap Livestock Management, Groenlo, the Netherlands). Note: $\mathrm{Y}=\mathrm{X}$ diagonal line displayed.

distributed within the $95 \%$ limits, with 1 outlier just outside these limits, and with no trend or heteroscedasticity (unequal variance) evident. Therefore, we found a high degree of agreement for identifying cow grazing activity. This relationship is consistent with the Pearson correlation of 0.88 and $\mathrm{CCC}$ of 0.75 reported by Bikker et al. (2014) when they compared visual observations with eating time estimates of a SensOor ear tag device (CowManager BV, Gerverscop, the Netherlands). In another study with the Smarttag Neck device, Van Erp-Van der Kooij et al. (2016) reported a Pearson

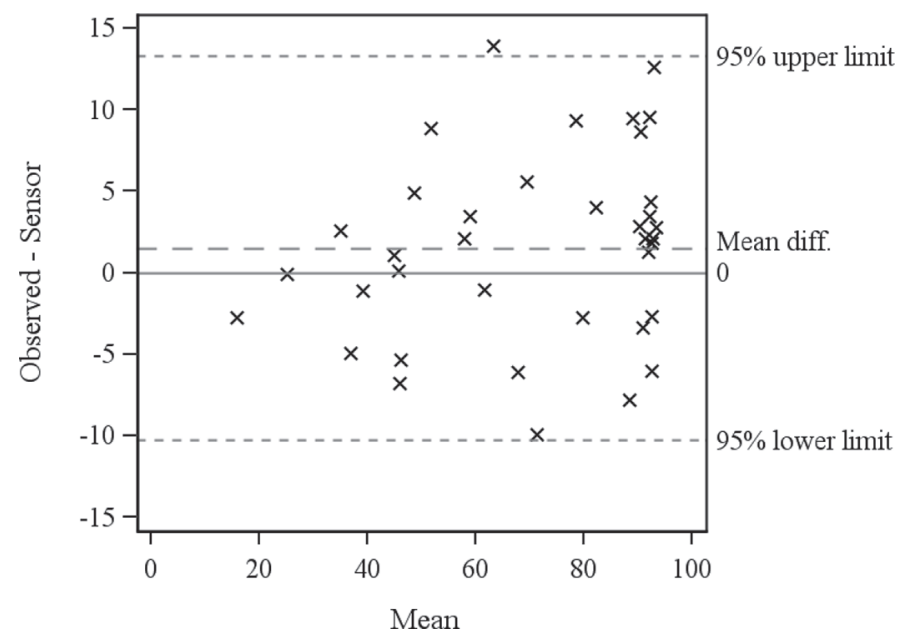

Figure 2. Bland-Altman plot of the data from Figure 1, showing mean difference (diff.) of 1.50 percentage points, no trend, no outliers, and uniform variation. 
a

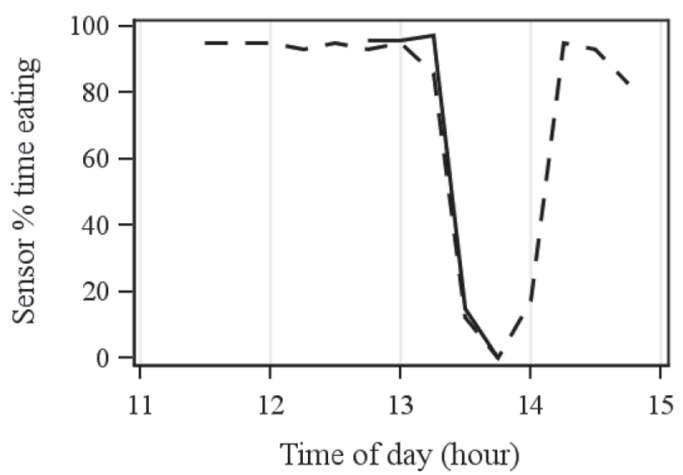

$\mathrm{b}$

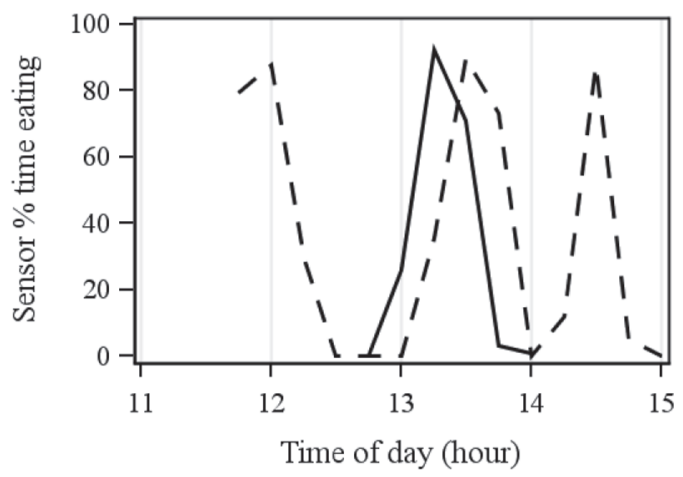

Figure 3. Minutes classified as grazing in 15-min intervals by the Smarttag "eating time" sensor (Nedap Livestock Management, Groenlo, the Netherlands; dashed line) compared with observed time spent actively grazing (solid line) in 2 selected observation periods.

correlation of 0.80 and $\mathrm{CCC}$ of 0.89 between visual observations and sensor estimations of eating behavior.

Figure 3a illustrates the observation period for an individual cow where sensor and observed data were well matched. In Figure 3b, however, the effect of the offset is shown (i.e., although the pattern of behavior is well matched, the sensor data are offset up to 15 min). However, for both plots the sensor and observed averages over the observation periods match very well.

The overall time spent exhibiting each of the recorded behaviors was B1 3\%, B2 24.4\%, B3 70.8\%, B4 0.8\%, and B5 1\%. When all head down behavior data were included (B3, B4, and B5), the relationship was very similar to B3 alone (Pearson correlation 0.972, CCC 0.961, mean difference 3.28 percentage points, SD 5.73 percentage points), with similar agreement and a slightly higher difference due to B4 (0.78\%) and B5 (0.99\%) being included. Thus, the Smarttag eating time sensors more correctly identified active grazing time only (i.e., B3). Therefore, Smarttag sensors are valid and could be a useful tool for researchers and pasture-based farmers to estimate grazing time on an individual cow and herd basis over periods of $1 \mathrm{~h}$ or more.

In conclusion, Smarttag sensor-identified eating time and observed grazing time for pasture-based dairy cows were very well correlated. The agreement was very high for data collated over 90-min observation periods from the 15-min intervals provided by the sensor. For research, use of only 15-min data is not recommended, due to issues with offset time stamping; however, the aggregation of data over 4 or more such periods reduces sampling variation considerably for this type of data. Although hourly data may be useful in investigating short-term temporal change, once fitted, Smarttag sensors are able to provide data over much longer (e.g., 24h) periods and therefore can be used with even greater confidence.

\section{ACKNOWLEDGMENTS}

This study was supported by funds from New Zealand dairy farmers through DairyNZ Inc. (Hamilton, NZ) in partnership with Ministry for Primary Industries Primary Growth Partnership (Wellington, New Zealand) funding. The authors thank DairyNZ technical staff based at Westpac Taranaki Agricultural Research Station (Hawera, New Zealand). We also thank GEA Technologies (Hamilton, New Zealand) and Nedap Livestock Management (Groenlo, the Netherlands) for use of their sensors and associated technical support. No funding was received from either GEA or Nedap. The authors have not stated any conflicts of interest.

\section{REFERENCES}

Bikker, J. P., H. van Laar, P. Rump, J. Doorenbos, K. van Meurs, G. M. Griffioen, and J. Dijkstra. 2014. Technical note: Evaluation of an ear-attached movement sensor to record cow feeding behavior and activity. J. Dairy Sci. 97:2974-2979. https://doi.org/10.3168/ jds.2013-7560.

Chizzotti, M. L., F. S. Machado, E. E. L. Valente, L. G. R. Pereira, M. M. Campos, T. R. Tomich, S. G. Coelho, and M. N. Ribas. 2015. Technical note: Validation of a system for monitoring individual feeding behavior and individual feed intake in dairy cattle. J. Dairy Sci. 98:3438-3442. https://doi.org/10.3168/jds.2014-8925.

Eckelkamp, E. A., and J. M. Bewley. 2020. On-farm use of disease alerts generated by precision dairy technology. J. Dairy Sci. 103:1566-1582.

Elischer, M. F., M. E. Arceo, E. L. Karcher, and J. M. Siegford. 2013. Validating the accuracy of activity and rumination monitor data from dairy cows housed in a pasture-based automatic milking system. J. Dairy Sci. 96:6412-6422. https://doi.org/10.3168/jds.2013 -6790 .

Greenwood, P. L., P. Valencia, L. Overs, D. R. Paull, and I. W. Purvis. 2014. New ways of measuring intake, efficiency and behaviour of grazing livestock. Anim. Prod. Sci. 54:1796-1804. https://doi.org/ 10.1071/AN14409.

Hut, P. R., A. Mulder, J. van den Broek, J. H. J. L. Hulsen, G. A. Hooijer, E. N. Stassen, F. J. C. M. van Eerdenburg, and M. Nielen. 2019. Sensor based eating time variables of dairy cows in the transition period related to the time to first service. Prev. Vet. Med. 169:104694. https://doi.org/10.1016/j.prevetmed.2019.104694. 
Moreau, M., S. Siebert, A. Buerkert, and E. Schlecht. 2009. Use of a tri-axial accelerometer for automated recording and classification of goats' grazing behaviour. Appl. Anim. Behav. Sci. 119:158-170. https://doi.org/10.1016/j.applanim.2009.04.008.

Nielsen, P. P. 2013. Automatic registration of grazing behaviour in dairy cows using 3D activity loggers. Appl. Anim. Behav. Sci. 148:179-184. https://doi.org/10.1016/j.applanim.2013.09.001.

Oudshoorn, F. W., C. Cornou, A. L. F. Hellwing, H. H. Hansen, L. Munksgaard, P. Lund, and T. Kristensen. 2013. Estimation of grass intake on pasture for dairy cows using tightly and loosely mounted di- and tri-axial accelerometers combined with bite count. Comput. Electron. Agric. 99:227-235. https://doi.org/10 .1016/j.compag.2013.09.013.

Penning, P. D. 1983. A technique to record automatically some aspects of grazing and ruminating behaviour in sheep. Grass Forage Sci. 38:89-96. https://doi.org/10.1111/j.1365-2494.1983.tb01626.x.

Pereira, G. M., B. J. Heins, and M. I. Endres. 2018. Technical note: Validation of an ear-tag accelerometer sensor to determine rumination, eating, and activity behaviors of grazing dairy cattle. J. Dairy Sci. 101:2492-2495. https://doi.org/10.3168/jds.2016-12534.
Roelofs, J. B., C. Krijnen, and E. van Erp-van der Kooij. 2017. The effect of housing condition on the performance of two types of activity meters to detect estrus in dairy cows. Theriogenology 93:12-15. https://doi.org/10.1016/j.theriogenology.2017.01.037.

Skenandore, C. S., and F. C. Cardoso. 2017. The effect of tail paint formulation and heifer behavior on estrus detection. Int. J. Vet. Sci. Med. 5:113-120. https://doi.org/10.1016/j.ijvsm.2017.08.001.

Van Erp-Van der Kooij, E., M. Van de Brug, and J. B. Roelofs. 2016. Validation of Nedap Smarttag Leg and Neck to assess behavioural activity level in dairy cattle. Pages 321-326 in Proc. International Precision Dairy Farming Conference. Wageningen Academic Publishers, Leeuwarden, the Netherlands.

\section{ORCIDS}

C. R. Eastwood ๑ https://orcid.org/0000-0002-1072-5078

K. A. Macdonald ๑ https://orcid.org/0000-0001-9842-0107 